\title{
Notifiable disease surveillance in Sri Lanka and the United Kingdom: a comparative study
}

\author{
Kalpana Chandrasekar B.Sc.(Hons.) (Jaffna), M.Sc.(LIS) (Madras), M.Phil.(Biochemistry) (Jaffna) \\ Senior Assistant Librarian, University of Jaffna, Jaffna, Sri Lanka \\ E-Mail address: kchandrasekar68@gmail.com
}

Sinnathamby Mahesan B.Sc.(Hons.)(Jaffna), M.Sc.(Cardiff), Ph.D.(Wales)

Senior Lecturer, Department of Computer Science Faculty of Science, University of Jaffna, Jaffna, Sri Lanka E-Mail address: mahesans@jfn.ac.lk

Peter A. Bath B.Sc. (Hons.)(Technical) (University of Wales), M.Sc.(Sheffield), Ph.D.(Sheffield)

Professor of Health Informatics, Information School, University of Sheffield, Sheffield, UK

E-Mail address: p.a.bath@ sheffield.ac.uk

Sri Lanka Journal of Bio-Medical Informatics 2013;4(1):14-22

doi: http://dx.doi.org/10.4038/sljbmi.v4i1.5190

\begin{abstract}
Threats posed by new, emerging or re-emerging infectious diseases are taking a global dimension. These diseases are a leading cause of morbidity and mortality around the world and have an influence on the economic growth and development of nations. Several evaluation studies on existing infectious disease surveillance systems (passive and/or active) have been undertaken to identify the strengths and weaknesses in order to improve surveillance activities. Research is also directed towards identifying specific factors that influence the information flow in the notification process of infectious diseases at different levels, such as completeness, timeliness, sensitivity, etc. Studies reported from Sri Lanka and the United Kingdom are very limited. Further, we rarely find any literature on comparative studies on disease surveillance systems in two different geographical locations. In this study in-depth, semi-structured interviews were conducted to collect data, in Jaffna (Sri Lanka) and Sheffield (UK).

Participants were recruited from those who were engaged in work related to the notifiable disease surveillance system at a local level. This research paper reports the advantages and disadvantages of the existing notifiable disease surveillance systems in the United Kingdom and Sri Lanka. In addition, it recommends that receiving notifications from various other sources (including indigenous medical practitioners, public health workers, laboratories and the general public), involvement of laboratories in disease surveillance activities, and computerising the existing surveillance system for notification would enhance the completeness and timeliness of reporting. In addition to epidemiological publications at national level, this study emphasises the importance of regional publications on notifiable disease surveillance.
\end{abstract}

Keywords - communicable disease surveillance; disease notification; infectious diseases; notifiable disease surveillance systems; comparison of disease surveillance systems

\section{Introduction}

The world today is largely characterised by globalisation, connectivity and speed. However, the control of the spread of communicable diseases is still a challenge ${ }^{(1)}$. Notifiable disease reporting systems provide the basis for surveillance of communicable diseases. In this study, the existing notifiable disease surveillance system in the United Kingdom is compared with the system in Sri Lanka. Several evaluation studies to identify the strengths and weaknesses of existing infectious disease surveillance systems (passive and/or active) have been reported $^{(2,3,4,5,6,7,8,9)}$. However, the literature on comparative studies on disease surveillance systems in two different geographical locations is very limited. Nevertheless, this type of 
comparative studies is expected to reveal the merits and demerits of the two different systems under study and has the potential to improve the quality of the existing infectious disease surveillance systems in both locations. The principal objective of this study was to explore the merits and demerits of the existing surveillance system for reporting of notifiable diseases in Sri Lanka and compare it with that in the United Kingdom, with a view to improving its quality.

\section{Research Methods}

Research design: This study was carried out in well-defined geographical locations in Sri Lanka and the United Kingdom. The participants in the studies were the staff concerned with the reporting (notification and investigation) process of the notifiable disease surveillance systems. A qualitative approach, using in-depth, semi-structured interviews was chosen to obtain information about their perceptions of problems with the existing system for reporting of notifiable diseases and suggestions for improvement in performance.

Recruitment of participants: Participants for the study were recruited from Jaffna and Sheffield. The main criterion was to be engaged in work related to the notifiable disease surveillance system at a local level.

Medical Practitioners (from government and private medical institutions) and staff of the Public Health Services, and those involved in the recording and reporting of notifiable diseases in the Jaffna District, participated in this study. Health services in the Jaffna District are delivered to a population of approximately 653,700 (as at 31 December 2006), through 11 Medical Officers of Health (MOH) units, 105 allopathic, and 116 indigenous medical institutions located (both in the government and private sectors). The total number of western and indigenous medical institutions comprised in each sector of the Jaffna District is illustrated in Figure 1.

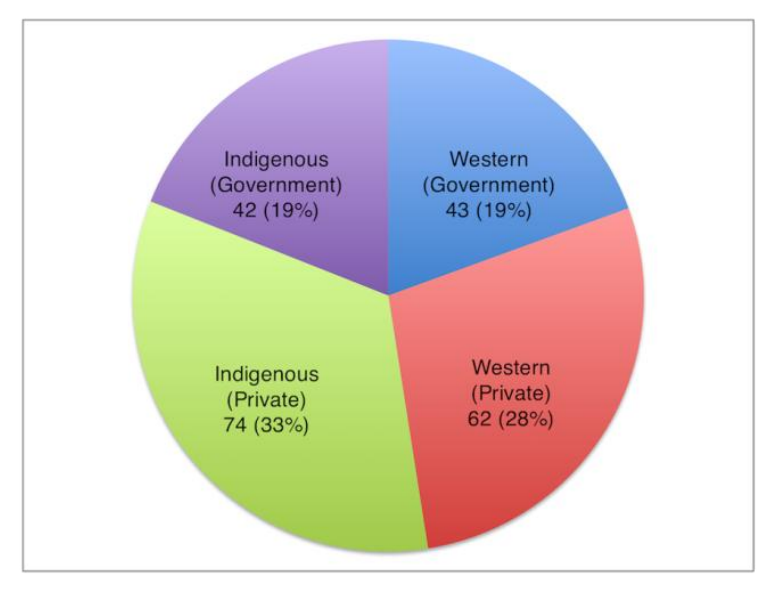

Figure 1. Distribution of healthcare institutions in Jaffna District, Sri Lanka

A list consisting of the names of Public Health Workers, Western Medical Practitioners and Indigenous Medical Practitioners was prepared with help from various sources. From the list, 100 were selected randomly and invited to participate in the study, considering the different staff categories and MOH divisions in Jaffna. Out of these 100 invitees, 38 staff consisting of 20 notifiers, 12 reporting staff and six administrative staff, as detailed in Table 1, participated in the study having accepted our invitation. 


\begin{tabular}{|c|c|c|c|c|}
\hline Categories & \multicolumn{2}{|l|}{ Jaffna } & \multicolumn{2}{|l|}{ Sheffield } \\
\hline Notifiers & $\begin{array}{l}\text { Medical } \\
\text { Practitioners (Western \& } \\
\text { Indigenous) } \\
\text { Medical Laboratory } \\
\text { Technicians }\end{array}$ & $\begin{array}{l}18 \\
02\end{array}$ & $\begin{array}{l}\text { General Practitioners } \\
\text { Doctors (in hospitals) } \\
\text { Microbiologists }\end{array}$ & $\begin{array}{l}02 \\
02 \\
01\end{array}$ \\
\hline Reporting staff & $\begin{array}{l}\text { Public Health Staff } \\
\text { Medical record keeping } \\
\text { officers (in hospitals) }\end{array}$ & $\begin{array}{l}10 \\
02\end{array}$ & $\begin{array}{l}\text { Environmental Health Officers } \\
\text { Information officer }\end{array}$ & $\begin{array}{l}02 \\
01\end{array}$ \\
\hline $\begin{array}{l}\text { Administrative } \\
\text { Officers }\end{array}$ & $\begin{array}{l}\text { Consultant } \\
\text { Epidemiologists } \\
\text { RDHS } \\
\text { Regional Epidemiologist } \\
\text { (Actg.) } \\
\text { Director/JTH } \\
\text { Consultant (WHO) }\end{array}$ & $\begin{array}{l}02 \\
01 \\
01 \\
\\
01 \\
01\end{array}$ & $\begin{array}{l}\text { Consultants (South Yorkshire } \\
\text { Health Protection Unit) }\end{array}$ & 01 \\
\hline
\end{tabular}

Table 1. Summary of the recruitment of participants in Jaffna and Sheffield

The participants in the UK study were General Practitioners (GPs) from the then Sheffield Primary Care Trust and hospital doctors from Sheffield Teaching Hospitals Trust, Consultants and other staff from the South Yorkshire Health Protection Unit (SYHPU), and Environmental Health Officers (EHOs) and Information Officers from Sheffield City Council. In addition, a microbiologist from a medical laboratory was also recruited. Using information available on the web regarding GP Practices, a list of General practitioners and Practice managers currently working at the Sheffield district was prepared. The list comprised of 299 GPs and 74 Practice managers, of whom 100 GPs and 37 Practice managers were randomly selected and invited to participate in the study. Of these 137 invitees, nine staff consisting of five notifiers, three reporting staff and one administrative staff, as detailed in Table 1, participated in the study.

Data collection and analysis: In-depth, semi-structured interviews were conducted as per the interview guide. A total of 47 interviews (38 in Jaffna and nine in Sheffield) were conducted. All the interviews (25-50 minutes of duration) were tape-recorded with the participants' consent and fully transcribed, assuring privacy and confidentiality issues. The results obtained from thematic analysis were used to compare the notifiable disease surveillance systems in the two different locations.

\section{Results and discussion}

Legal requirement for the notification of certain infectious diseases was introduced towards the end of the $19^{\text {th }}$ century both in Sri Lanka and in the UK. Initially, only a few infectious diseases were reported. The number of reportable diseases has increased over the decades to 27 in Sri Lanka and 30 in the UK, and 21 of these are common for both countries. In the following sections, we discuss the sources of notification, surveillance to process and feedback mechanism in relation to existing surveillance systems in the UK and Sri Lanka, and compare the systems with regard to their merits and demerits and suggest how the system can be improved in Sri Lanka (Table 2). 


\begin{tabular}{|c|c|c|c|}
\hline Components & UK system & SL system & Remarks \\
\hline Notifiers & $\begin{array}{l}\text { General Practitioners } \\
\text { Doctors (in hospitals) } \\
\text { Microbiologists (from } \\
\text { laboratories) } \\
\text { General public }\end{array}$ & $\begin{array}{l}\text { Western Medical } \\
\text { Practitioners }\end{array}$ & $\begin{array}{l}\text { Incomplete notification is } \\
\text { common both in the UK and } \\
\text { SL, whereas reasons differ. In } \\
\text { the UK, it is due to lack of } \\
\text { priority for infectious disease } \\
\text { surveillance. However, in SL } \\
\text { participation in notification } \\
\text { except western medical } \\
\text { practitioners is inadequate. }\end{array}$ \\
\hline Proper officer & $\begin{array}{lr}\text { Consultant } & \text { in } \\
\text { Communicable } & \text { Disease } \\
\text { Control (CCDC) } & \end{array}$ & $\begin{array}{l}\text { Medical Officer of health } \\
(\mathrm{MOH})\end{array}$ & \\
\hline Information flow & Figure 2 & Figure 3 & $\begin{array}{l}\text { Figures show the flow of } \\
\text { information among various } \\
\text { entities. }\end{array}$ \\
\hline $\begin{array}{l}\text { Laboratory } \\
\text { involvement in } \\
\text { notification }\end{array}$ & $\begin{array}{l}\text { Medical laboratories } \\
\text { involve in } r \text { disease } \\
\text { notification to } \text { CCDC } \\
\text { and public health } \\
\text { laboratories support for } \\
\text { investigation. }\end{array}$ & $\begin{array}{l}\text { Medical laboratories report } \\
\text { back to the medical } \\
\text { practitioners who requested } \\
\text { the lab tests. Public health } \\
\text { laboratories are not existing } \\
\text { at regional level. }\end{array}$ & $\begin{array}{l}\text { Completeness and timeliness } \\
\text { of reporting in disease } \\
\text { surveillance activities can be } \\
\text { improved with direct } \\
\text { laboratory notification to a } \\
\text { proper officer. }\end{array}$ \\
\hline $\begin{array}{l}\text { Feedback } \\
\text { mechanism }\end{array}$ & $\begin{array}{l}\text { Health Protection Report } \\
\text { published by the health } \\
\text { protection Authority } \\
\text { HPA, at national level }\end{array}$ & $\begin{array}{l}\text { Weekly Epidemiological } \\
\text { Report (WER) and } \\
\text { Quarterly Epidemiological } \\
\text { Bulletin (QEB) published } \\
\text { by the Epidemiology unit, } \\
\text { at national level }\end{array}$ & $\begin{array}{l}\text { Epidemiological publications } \\
\text { at regional level are required } \\
\text { for dissemination of regional } \\
\text { information }\end{array}$ \\
\hline $\begin{array}{l}\text { Data processing, } \\
\text { communication } \\
\text { and information } \\
\text { sharing }\end{array}$ & $\begin{array}{l}\text { Paper-based, plus } \\
\text { information sharing by } \\
\text { electronic means }\end{array}$ & $\begin{array}{l}\text { Fully paper-based and } \\
\text { communication by post }\end{array}$ & $\begin{array}{l}\text { Timeliness of reporting is } \\
\text { improved } \\
\text { through } \\
\text { computerisation }\end{array}$ \\
\hline
\end{tabular}

Table 2. Comparison of the components of the surveillance process in the UK and Sri Lanka

Sources of notification: In the UK, the responsibility for reporting diseases to the local 'proper officer' was on the head of the family or landlord at the beginning, but later this was restricted to the attending medical practitioner, either in the patient's home or surgery or hospital. However, it was observed that medical practitioners do not give priority to notifiable disease reporting, as communicable diseases are not a major health problem in the developed world compared to developing countries like Sri Lanka. Further, medical laboratories in the UK are also involved in surveillance activities, by sending the laboratory reports related to notifiable diseases to the local 'proper officer' (known as CCDC - Consultant in Communicable Disease Control) directly. As this process is slow (due to the time taken for confirmatory tests), they usually inform the CCDC immediately over the phone in case of an emergency. Apart from this formal reporting of notifiable diseases, sometimes informal notifications are also received at local authorities (City Councils or Local Health Protection Units) from schools, employers and the public. 
According to the Quarantine and Prevention of Diseases Ordinance introduced in 1897 and its subsequent amendments ${ }^{(10)}$ in Sri Lanka, a medical practitioner, or any person qualified to treat diseases should notify immediately when they encounter a patient with a notifiable disease mentioned in the 'list of notifiable diseases' to the 'proper authority' (known as MOH - Medical Officer of Health). Public health workers also occasionally detect and report cases with notifiable conditions during their field visits. In addition, civil service officers, educational institutions, family members and neighbours are expected to notify these diseases during major epidemics. However, except for western medical practitioners in government hospitals, notification from other sources (including western medical practitioners from the private sector and indigenous medical practitioners) is very limited. Thus, the completeness of notification is not satisfactorily achieved. It would be evident from the above discussion with regard to sources of notification, introducing direct laboratory notification to $\mathrm{MOH}$ would help to improve the timeliness and completeness of notifiable disease reporting in Sri Lanka. Improving timeliness would be achieved, if a case of notifiable condition is reported immediately with a clinical diagnosis, even before it is confirmed with the laboratory reports. Moreover, laboratory reporting would act as a double-check for notification received from medical practitioners, and thus it would enhance the completeness of notification. Further, informal reporting (via telephone) from educational institutions, civil service officers and general public to respective MOHs (in Sri Lanka) should also be encouraged, in order to complete reporting of communicable disease incidences.

Surveillance process: Allopathic system of medicine is predominantly used in the UK. The existing surveillance system for notifiable diseases in the UK is illustrated in Figure 2.

Regarding infectious disease notification, food and water borne diseases are reported to the local authority and other notifiable diseases are reported to Local Health Protection Unit (LHPU) by filling the notification card manually by the medical practitioners and posting it to the respective CCDC or any other person appointed by the local authority for this purpose.

However, it was reported by many participants that electronic notification be an advantage as GP practices in the UK are moving towards paperless systems, preferably with an electronic signature for authorisation wherever necessary. In 2009, an electronic version of the 'Enhanced Tuberculosis surveillance form' was introduced by the Health Protection Agency (HPA) for the first time. In relation to this, Sheffield City Council also posted a 'Suspected food poisoning report form' on their website, to encourage the public to get involved in notification.

On receipt of notifications, consequently, notifications related to food and water borne diseases are handled by the EHOs at the local authority and notifications of other infectious diseases are dealt by the Health Protection Nurses at the LHPU. The public health laboratories in the UK support Environmental Health Officers (EHO) and Health Protection Nurses in disease confirmation. In Sheffield, initially notifications are received by the Information Officer (at the local authority) and Surveillance Officer (at the LHPU) who feed them into the surveillance system which are transferred to the EHOs and Health Protection Nurses respectively, for further action. These public health officials then decide whether appropriate questionnaires related to specific diseases should be sent out to patients or a visit to the patient's house is required or the food establishment needs to be inspected. Subsequently, relevant information is updated in the databases at the local authority and LHPU, by the Information Officer and the Surveillance Officer respectively, and then, these surveillance data would be exchanged between the two institutions and HPA. The exchange 
is secure, password protected and reserved for those people who are involved in that particular work. NOIDs (Notification of Infectious Diseases) reports are generated on a weekly basis at LHPUs from the database system and sent to the Centre for Infections.

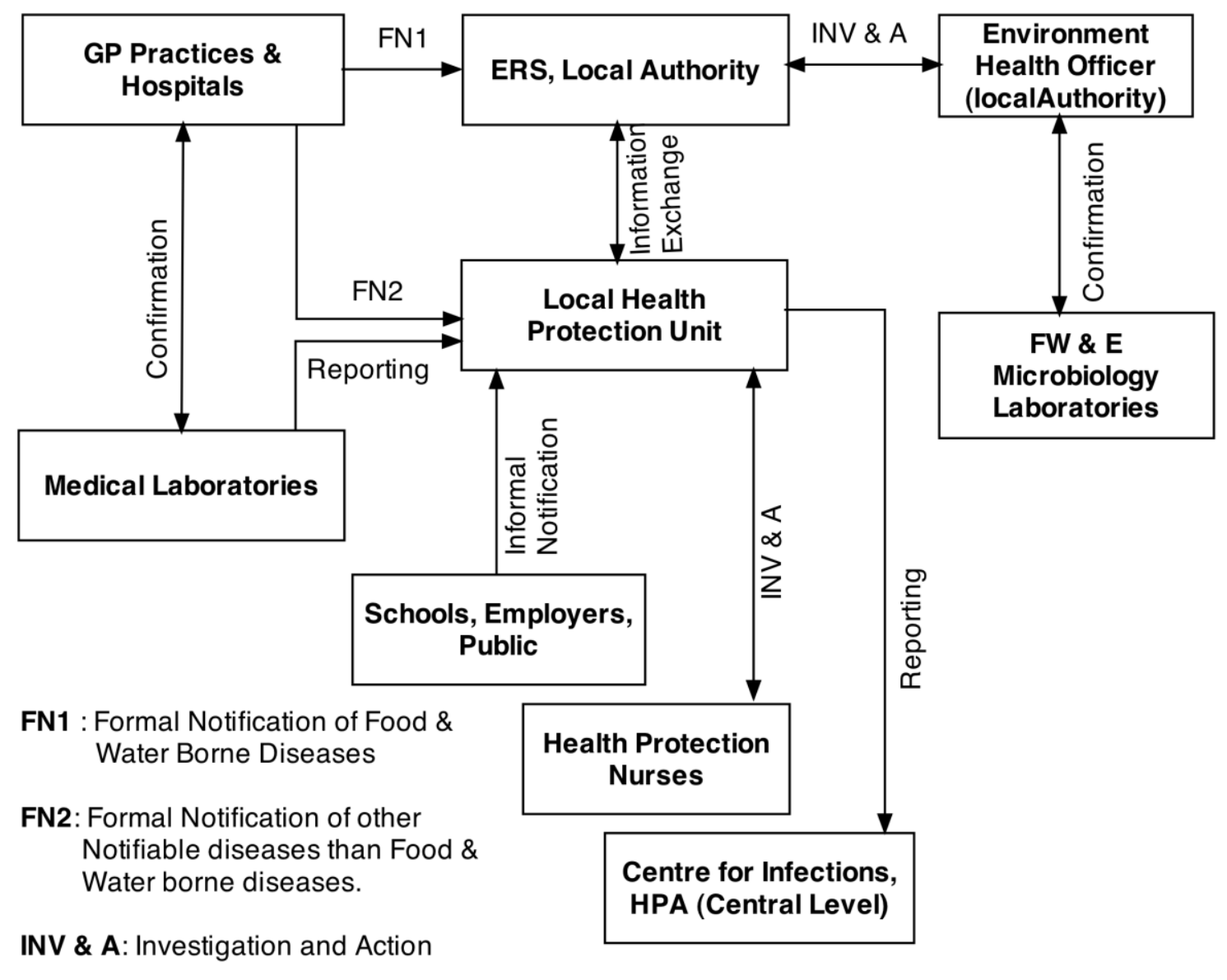

Figure 2. Mechanism of data collection for notifiable disease surveillance in the UK

In Sri Lanka, along with the allopathic system of medicine, the Siddha, Ayurveda, Unani, Acupuncture and Homeopathy systems are also practised. However, the allopathic system is mainly followed for treating notifiable diseases. People prefer Siddha or Ayurveda treatment for some notifiable diseases such as hepatitis or measles, yet notifications from the indigenous medical practitioners is rather poor mainly due to the lack of a system for notification which leads to incomplete reporting of infectious diseases. Further, in Sri Lanka, usually notifications of all the communicable diseases as per the list of notifiable diseases are sent to the $\mathrm{MOH}$ of the area where the patient resides. This surveillance process is depicted in Figure 3.

On receipt of these notifications at $\mathrm{MOH}$ offices, details are recorded in the Notification Register and then distributed to respective Public Health Inspectors (PHIs) of the area for investigation and further action. After investigation, the PHIs usually submit their investigation reports of confirmed cases to the $\mathrm{MOH}$ for further processing.

Subsequently, information in these reports is transferred to several forms and registers, before it ends up in the preparation of the WRCD (Weekly Report of Communicable Diseases) on a weekly basis. All these activities are performed manually and it is noticed that a number of details are repeated in more than one surveillance tool. As such, it becomes a labour-intensive 
and time-consuming process. When comparing the two systems, it is noted that the Sri Lankan system lacks the involvement of public health laboratories in the investigation. There are no public health laboratories at present in Jaffna to support PHIs in investigations.

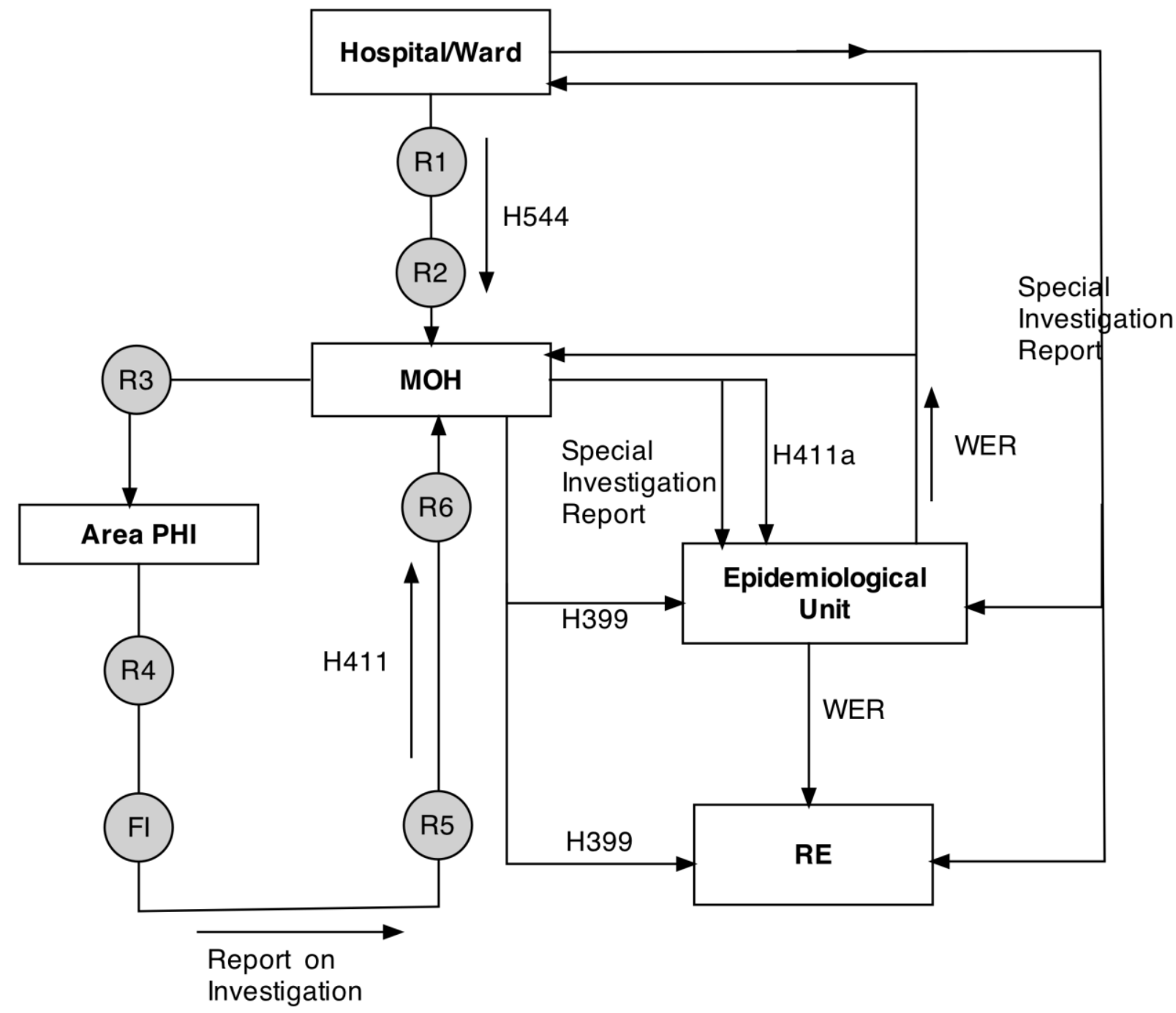

Where $\mathrm{R} 1-\mathrm{R} 6$ are registers at respective places:

R1 - Ward notification Register

R2 - Institutional Notification Register

R3 - MOH office Notification Register

R4 - Letter inward Register

R5 - Letter outward Register

R6 - MOH Infectious Diseases Register $(\mathrm{H} 700)$
FI means Field investigation

$\mathrm{H} 544, \mathrm{H} 411$ and $\mathrm{H} 399$ are specific forms to be filled and to be sent

WER - Weekly Epidemiological Report

RE - Regional Epidemiologist

Figure 3. Notifiable disease surveillance system in Sri Lanka

Hence, if notification is based on probable diagnosis then confirming the disease during investigation would be difficult for PHIs, if not impossible. Moreover, medical laboratories usually send their reports to the respective medical practitioner who referred the patient for 
the investigation. On most occasions, medical practitioners notify the cases based on these laboratory reports, and that results in delays.

However, it was observed that certain special laboratories in Colombo are reporting the confirmed cases to the Epidemiology Unit directly on a regular basis. Furthermore, most of the health staff at both locations preferred the computerised surveillance system for notifiable diseases due to the advantages such as speed in information delivery, better accessibility, easy record maintenance and report creation. In this context, the Notifiable Disease Surveillance System (NDSS) in the UK is computer-aided and/or partly-computerised, whilst Sri Lanka still depends on a paper-based system. In the semi-automatic system of the UK surveillance process, though many functions are still performed manually, the computerisation of storage and retrieval of data reduce delays.

Feedback mechanism: Epidemiological publications published at national level are considered as a source of feedback for surveillance data provided at regional and local levels, at both locations. In the UK, the 'Health Protection Report' is published by the HPA (at a national level) on a weekly basis and is accessible for authorised users through its website. Certain LHPUs also produce a quarterly newsletter for GPs which carries information related to different aspects of infectious diseases pertaining to that region. Regarding the SYHPU, in addition to these regular publications, e-mail alerts are also sent by the CCDC to health staff involved in notifiable disease surveillance activities during outbreaks. However, medical practitioners prefer feedback on individual cases reported by them, rather than these general publications.

In Sri Lanka, the 'Weekly Epidemiological Report' (WER) and 'Quarterly Epidemiological Bulletin' (QEB) published by the Epidemiology Unit (at national level) are the main sources of current epidemiological information. The utilisation of these publications among health professionals is restricted due to lack of awareness, delays in publication, the medium as a barrier, limited circulation and problems in accessibility.

Compared to Sri Lanka, accessibility to epidemiological publications is adequate in the UK, although the level of utilisation by the health professionals does not appear satisfactory. In Sri Lanka, adequate efforts should be taken at national level to ensure timeliness of release and to enhance the accessibility of these publications. In addition, one of the major drawbacks observed in the feedback mechanism at both locations is the lack of publications on epidemiological information at regional level. Thus, it is recommended to take action at regional level to collect, collate and publish epidemiological information at regular intervals.

In conclusion, this comparative study assessed the existing NDSS of Sri Lanka and the UK, and explored the features that would be applied to develop an information system suitable for the surveillance of notifiable diseases in Sri Lanka. Completeness and timeliness of reporting are two essential features which need to improve in any disease surveillance system. In order to achieve completeness, this study identified various sources of notification in Sri Lanka, in addition to current notifiers. Further, laboratory involvement in surveillance activities is recognised to be important as it improves completeness and timeliness of disease reporting. Furthermore, computerisation of the existing surveillance system is also identified as an advantage over paper-based systems, in enhancing the timeliness of reporting. This study also emphasised the importance of regional level publications related to communicable disease surveillance activities. 


\section{Acknowledgement}

We thank all the participants of this study for their support. Financial assistance was obtained under a Commonwealth Split-site Doctoral Scholarship tenable in the UK.

\section{References}

1. Heymann DL. (Editor). Control of communicable diseases manual. 18th edition. New York: American Public Health Association 2004.

2. Awad R, Al Rahman Omer A, Abu Shahla N. A critical review of the infectious diseases surveillance system in the Gaza Strip. Eastern Mediterranean Health Journal 2001; 7(1/2): 274-9.

3. Kimball AM, Thacker SB, Levy ME. Shigella surveillance in a large metropolitan area: assessment of a passive reporting system. American Journal of Public Health 1980; 70(2): 164-6.

doi: http://dx.doi.org/10.2105/AJPH.70.2.164

4. Miller M, Roche P, Spencer J, Deeble M. Evaluation of Australia's National Notifiable Disease Surveillance System. Communicable Diseases Intelligence 2004; 28(3): 31123.

5. Thacker SB, Choi K, Brachman PS. The surveillance of infectious diseases. The Journal of the American Medical Association 1983; 249(9): 1181-5.

doi: http://dx.doi.org/10.1001/jama.1983.03330330059036

6. Vogt RL, LaRue D, Klaucke DN, Jillson DA. Comparison of an active and passive surveillance system of primary care providers for Hepatitis, Measles, Rubella, and Salmonellosis in Vermont. American Journal of Public Health 1983; 73(7): 795-7. doi: http://dx.doi.org/10.2105/AJPH.73.7.795

7. Doyle TJ, Glynn MK, Groseclose SL. Completeness of notifiable infectious disease reporting in the United States: an analytical literature review. American Journal of Epidemiology 2002; 155(9): 866-74.

doi: http://dx.doi.org/10.1093/aje/155.9.866

8. Goldacre MJ, Miller DL. Completeness of statutory notification for acute bacterial meningitis. British Medical Journal 1976; 2: 501-3.

doi: http://dx.doi.org/10.1136/bmj.2.6034.501

9. Green MS, Kaufman Z. Surveillance for early detection and monitoring of infectious disease outbreaks associated with bioterrorism. Israel Medical Association Journal 2002; 4:503-6.

10. Government of Ceylon. Legislative enactments of Ceylon (1956 revision): quarantine and prevention of diseases ordinance. Colombo: The Government Publications Bureau, 1960. 